\title{
Let's Look Right during Diastolic Dysfunction Evaluation?
}

\author{
Murilo Foppa ${ }^{1,2}$ and Angela Barreto Santiago Santos ${ }^{1,2}$ \\ Hospital de Clinicas de Porto Alegre, ${ }^{1}$ Porto Alegre, $R S$ - Brazil \\ Universisade Federal do Rio Grande do Sul, ${ }^{2}$ Porto Alegre, RS - Brazil
}

Nearly half of heart failure patients have preserved ejection fraction (HFPEF). ${ }^{1}$ HFPEF is traditionally attributed to an increased left ventricular end-diastolic filling pressure $(\mathrm{Pd} 2)$, triggered by structural, metabolic and functional mechanisms. Echocardiography permits to identify HFPEF signs as diastolic dysfunction (DD), ${ }^{2}$ enlarged left atrium, and more subtle abnormalities of systolic function detected by global longitudinal strain. ${ }^{3,4}$ Right ventricular (RV) abnormalities and pulmonary hypertension are also identified by echocardiography and are frequently seen in HFPEF. ${ }^{5}$ However, there are controversies if the abnormalities seen in right cardiac chambers are a consequence of left-sided abnormalities or if they correspond to a direct effect over left and right chambers simultaneously, caused by the same mechanisms, such as diffuse subendocardial fibrosis and subclinical systolic dysfunction.

In this journal, Baroncini et al. ${ }^{6}$ sought to bring more evidence to fill this knowledge gap. The authors compared two small samples of individuals with and without DD (25 subjects in each group) and found no significant changes in RV function between the groups measured by tricuspid annular plane excursion (TAPSE) or RV free wall systolic velocity $\left(s^{\prime}\right)$. The secondary analysis highlighted by the authors showed that in the subgroup with DD, the 7 individuals with a dilated left atrium presented worse RV function parameters compared to the other patients with DD $(n=18)$. These results could suggest that RV abnormalities would be present only in those already with a chronic increase in left atrial pressure identified by its dilatation.

\section{Keywords}

Heart Failure; Stroke; Ventricular Dysfunction Right; Atrial Function; /physiology; Echocardiography/methods; Hypertension.

Mailing Address: Murilo Foppa •

Hospital de Clinicas de Porto Alegre - Rua Ramiro Barcelos, 2350. Postal Code 90035-903, Porto Alegre, RS - Brazil

E-mail: mufoppa@hcpa.edu.br

DOI: $10.5935 / a b c .20190053$
However, this specific finding in one subgroup is very likely to have occurred by chance. In addition to the recognized caveats of a posteriori findings, there are other reported findings that weaken the consistency of the biological plausibility of the association described. There was no significant correlation when measurements of the left atrium and right ventricle were analyzed continuously (unlike the article title), neither there was any relevant association identified in the analyzes that included the group of supposedly normal controls. Another important issue is the impossibility of the study, as performed, to adequately adjust for the intricate relationships between confounding variables. This is evident when we analyze the relationships between age, diastolic function, left atrial size and diastolic function in the study.

Alterations in RV function at early stages of DD has already been studied, when the effects of pulmonary circulation on RV have not yet been observed. Brand et al. ${ }^{7}$ studying 438 women (BNP $=34.4 \pm 31.6 \mathrm{pg} / \mathrm{ml}$, Pulmonary artery systolic pressure $=21.8 \pm 6.2 \mathrm{mmHg}$ ) showed the group with DD ( $n=152$ ) had worse RV systolic function compared to the group without DD $(n=286)$, either by conventional measures such as TAPSE, S', and fractional area change, or by newer methods such as global and free wall RV strain. It is noteworthy that the group with DD had no echocardiographic signs of increased left ventricular filling pressures, RV dilatation, or pulmonary hypertension, reinforcing the physiopathological concept that the occurrence of RV dysfunction is independent of the pressure overload in this cavity.

The advances in HFPEF knowledge is indisputable, demonstrating the global cardiac, pulmonary, and multisystemic involvement in the syndrome, beyond that of DD. This was largely achieved with the help of noninvasive imaging and is likely to help in the identification of treatment targets and prevention strategies. On the other hand, despite its universal clinical use, the independent diagnostic and prognostic role of any imaging biomarker used individually is still a matter of debate, due to their complex interconnections. Considering this, it is paramount the proper discernment between associations, causality, and clinical utility of any biomarker, particularly in the echocardiographic evaluation of DD. 


\section{Short Editorial}

\section{References}

1. Owan TE, Hodge DO, Herges RM, Jacobsen SJ, Roger VL, Redfield MM. Trends in prevalence and outcome of heart failure with preserved ejection fraction. N Engl J Med. July 2006;355:251-9.

2. Zile MR, Baicu CF, Gaasch WH. Diastolic heart failure-abnormalities in active relaxation and passive stiffness of left ventricle. N Engl J Med. May 6 2004;350:1953-9.

3. Kraigher-Krainer E, Shah AM, Gupta DK, Santos A, Claggett B, Pieske B, et al; PARAMOUNT Investigators. Impaired systolic function by strain imaging in heart failure with preserved ejection fraction. J Am Coll Cardiol. 2014;63(5):447-56.

4. Shah AM, Claggett B, Sweitzer NK, Shah SJ, Anand IS, Liu L, et al. Prognostic Importance of Impaired Systolic Function in HeartFailure with Preserved Ejection Fraction and the Impact of Spironolactone. Circulation. 2015;132(5):402-14.
5. Gorter TM, van Veldhuisen DJ, Bauersachs J, Borlaug BA, Celutkiene J, Coats AJS, et al. Right heart dysfunction and failure in heart failure with preserved ejection fraction: mechanisms and management. Position statement on behalf of the Heart Failure Association of the European Society of Cardiology. Eur J Heart Fail. 2018;20(1):16-37.

6. Baroncini LAV, Borges LJL, Camarozano AC. Carmo Dc, Darwich RZ, Fortunato Jr JA. Correlação ecocardiografica entre função ventricular direita e volume atrial esquerdo. Arq Bras Cardiol. 2019; 112(3):249-257.

7. Brand A, Bathe M, Oertelt-Prigione S, Seeland U, Rücke M, Regitz-Zagrosek $\mathrm{V}$, et al. Right heart function in impaired left ventricular diastolic function: 2D speckle tracking echocardiography-based and Doppler tissue imagingbased analysis of right atrial and ventricular function. Echocardiography. 2018;35(1):47-55. 